\title{
Increased HE4 mRNA Expression Correlates with High Level Of elF3a mRNA And Better Survival in Women with Epithelial Ovarian Cancer
}

\author{
Chen-Hui Luo ${ }^{1,2}$, Min Zhao1, Yu-Xi Tang 3 , Shohreh Shahabi ${ }^{4}$, Kai-Ning Fang 3 , Yan Chen ${ }^{3}$, Yan Tang 3 , \\ Xiao-Yan Chen ${ }^{5}$, Jing Wang ${ }^{3 凶}$, Hong-Hao Zhou ${ }^{1 凶}$
}

1. Department of Clinical Pharmacology, Institute of Clinical Pharmacology, Hunan Key Laboratory of Pharmacogenetics, Xiangya Hospital, Central South University, Changsha, Hunan, People's Republic of China;

2. Laboratory Animal Research Center, Hunan Cancer Hospital, the Affiliated Cancer Hospital of Xiangya School of Medicine, Central South University, Changsha, Hunan, People's Republic of China;

3. Department of Gynecologic Oncology, Hunan Cancer Hospital, the Affiliated Cancer Hospital of Xiangya School of Medicine, Central South University, Changsha, Hunan, People's Republic of China;

4. Department of Obstetrics and Gynecology, Division of Gynecologic Oncology, Prentice Women's Hospital, Northwestern University Feinberg School of Medicine, Chicago, IL, United States;

5. Department of Pathology, Hunan Cancer Hospital, the Affiliated Cancer Hospital of Xiangya School of Medicine, Central South University, Changsha, Hunan, People's Republic of China.

$\square$ Corresponding authors: Hong-Hao Zhou, MD, Institute of Clinical Pharmacology, Xiangya Hospital, Central South University, 110 Xiangya Road, Changsha 410008, Hunan, People's Republic of China (phone number: +86 7318480 5379, E-mail: hhzhou2003@163.com); and Jing Wang, MD, PhD, Department of Gynecologic Oncology, Hunan Cancer Hospital, The Affiliated Cancer Hospital of Xiangya School of Medicine, Central South University, 582 Xianjiahu Road, Changsha, 410013, Hunan, People's Republic of China (phone number: +86 7318865 1849, E-mail: wangjing189@163.com).

(c) Ivyspring International Publisher. This is an open access article distributed under the terms of the Creative Commons Attribution (CC BY-NC) license (https:// creativecommons.org/licenses/by-nc/4.0/). See http://ivyspring.com/terms for full terms and conditions.

Received: 2017.11.02; Accepted: 2018.02.14; Published: 2018.02.28

\begin{abstract}
Human epididymis protein 4 (HE4) is one of the most promising biomarkers for epithelial ovarian cancer (EOC). The majority of previous studies utilized the serum level or tissue protein expression of HE4 based upon immunohistochemistry (IHC) to evaluate the role of HE4 in the diagnosis, prognosis, and surveillance of EOC, but very little is known about HE4 mRNA expression. Eukaryotic translation initiation factor $3 \mathrm{a}$ (elF3a) is implicated in oncogenesis and has been investigated extensively as a potential biomarker for malignancy. We previously reported a positive correlation between IHC expressions of elF3a and HE4 in EOC. In the present study, we performed RT-PCR to determine mRNA expressions of HE4 and elF3a in 30 normal ovarian tissues, 45 benign, 20 borderline and 94 malignant ovarian tumors. The association of HE4 and elF3a mRNA expressions with clinicopathological characteristics and patient survivals was investigated. $\mathrm{IHC}$ was also performed in the same participants to investigate the correlation between mRNA and protein levels of HE4. HE4 mRNA level was found to be $48.42 \pm 74.55$ (mean \pm SD, range: 0.01-343.99), significantly higher in primary EOC than in the borderline tumor, benign tumor, and normal ovarian tissue $(\mathrm{P}<0.001)$. The cutoff value was 13.99 for HE4 to discriminate malignant from benign tumors at $68.1 \%$ sensitivity and $93.0 \%$ specificity. By Spearman's correlation test, HE4 mRNA expression was indicated to positively correlate with serum CA125 level $(r=0.530, P<0.001)$. Higher HE4 mRNA expression was associated with decreased frequency of lymph node metastasis $(P=0.038)$ and better overall survival $(O S)(P=0.007)$ in primary EOC. Multivariable analysis showed an independent prognostic value of the relative mRNA level of HE4 greater than one for OS (Hazard Ratio, $0.069,95 \% \mathrm{Cl}$, 0.009-0.530, $\mathrm{P}=0.010$ ). elF3a mRNA expression in women with primary EOC was $0.95 \pm 1.19$ (mean \pm $S D$, range: $0.06-7.46)$, which was in a positive linear correlation with HE4 mRNA expression $(r=0.310$, $\mathrm{P}=0.002$ ). In the present study, the HE4 mRNA level was unparalleled with IHC expression of HE4 $(P>0.05)$. Collectively, our study revealed that increased HE4 mRNA expression correlates with high level of elF3a mRNA and better survival in women with EOC, which calls for further investigations.
\end{abstract}

Key words: HE4, epithelial ovarian cancer (EOC), mRNA, overall survival, eIF3a 


\section{Introduction}

Epithelial ovarian cancer (EOC) is the leading cause of death from gynecologic cancer in the United States[1]. Human epididymis protein 4 (HE4) is regarded as one of the most promising serum biomarkers for ovarian cancer since 2003[2]. Numerous studies have found that HE4 is a more valuable serum biomarker than CA125 for EOC diagnosis and its recurrence[3-6]. By utilizing the serum levels or protein expressions of HE4, more findings have evaluated the role of HE4 protein in the diagnosis, prognosis, and surveillance of EOC[3-12]. Moreover, serum HE4 level is also reported to be a reliable marker for early diagnosis of endometrial[13], lung [14], and pancreatic cancer[15]. High levels of HE4 in the serum and high staining of HE4 in the tissue by IHC has made it important to determine the distribution of HE4 mRNA expression, to reveal the basis for protein. However, relevant research on HE4 mRNA is far from enough. Thus, additional studies are required to investigate the characteristics of HE4 mRNA expression and its possible association with clinicopathological variables and survivability in EOC.

Eukaryotic translation initiation factor $3 a$ (eIF3a) is the core subunit of the eIF3 complex, which is crucial for the initiation of mRNA translation, and links translation initiation to transcription[16, 17], to mRNA export[18], and to the nonsense-mediated decay pathway[19]. Aberrant eIF3a expression is implicated in oncogenesis [20] and is reported in a number of cancers including EOC[21-23]. eIF3a as a potential prognostic biomarker for malignancy is under extensive investigation[20-22]. We previously reported a pilot study on increased eIF3a expression detected by IHC in EOC and a positive correlation with HE4[23]. Thus, we hypothesized that there may be a similar correlation between mRNA expressions of eIF3a and HE4.

In the present study, we investigated the mRNA expressions of HE4 and eIF3a in women with primary EOC and their relationships with clinicopathological characteristics and survival of women with primary EOC.

\section{Materials and Methods}

\section{Patients and specimens}

Specimens and clinical data including serum CA125 levels were collected from ovarian cancer patients who had undergone initial surgery at the Hunan Cancer Hospital (Changsha, China) between August 2011 and April 2014. Inclusion criteria were (a) histologically confirmed EOC including three major histopathologic subtypes (serous, mucinous, and other adenocarcinoma); (b) treatment with platinum/taxane-based chemotherapy after debulking surgery; (c) no radiotherapy or biological therapy before the surgery; and (d) Karnofsky Performance Status (KPS) score $\geq 80$ prior to the surgery. Exclusion criteria included (a) metastatic or non-epithelial tumors in ovary; (b) active pelvic infection; and (c) symptomatic brain or leptomeningeal metastases. All patients were staged according to the International Federation of Gynecology and Obstetrics (FIGO) surgical staging system. Moreover, samples and data of normal and benign ovarian tumors were collected from patients who underwent surgery for benign or other malignant pathologies. In total, 189 patients (30 normal, 45 benign neoplasms, 20 borderline and 94 malignant tumors) were identified. Fresh tissue was collected and stored in liquid nitrogen for real-time qPCR, and paraffin samples were obtained for histological diagnosis and IHC analysis.

For prognostic factor evaluation, overall survival (OS) was defined as the interval in months between tumor resection and either death or the last observation. Progression free survival (PFS) was defined as the number of months from surgery to diagnosis of relapse or progression. Patients alive at the end of follow-up were censored. The protocol was approved by the Ethics Committee of Hunan Cancer Hospital (Changsha, China) and all patients provided written informed consent.

\section{Real-Time qPCR}

Total RNA was extracted from frozen patient tissues using the Trizol reagent (Thermo Fisher). RNA was reverse transcribed using the PrimeScript ${ }^{\mathrm{TM}} \mathrm{RT}$ reagent kit with gDNA Eraser (Takara), and RT-qPCR was carried out in a LightCycler ${ }^{\circledR} 480$ Real-Time PCR System using the SYBR Premix Ex TaqT ${ }^{\mathrm{TM}}$ (Tli RNaseH Plus) kit (Takara), according to the manufacturers' instructions. The primers were as follows: for eIF3a, 5'-TGATGAGGACAGAGGACCAAGAC-3' (forward) and 5'-TCAGCATTACGCCAGGATGA-3' (reverse); for HE4, 5'-ATAGCACCATGCCTGCTTGT-3' (forward) and 5'-TGCTCCTGTGCCTGAGACTA-3'(reverse); and for GAPDH control, 5'-GAAATCCCATCACCAT CTTCCAGG-3' (forward) and 5'-GAGCCCCAGCCTT CTCCATG-3' (reverse). GAPDH acted as the internal control. The relative mRNA levels of HE4 and eIF3a were defined by using the $2^{-\Delta \Delta} \mathrm{Ct}$ cycle threshold method.

\section{Immunohistochemistry (IHC)}

Tissue sections ( $4 \mu \mathrm{m}$ thick) were prepared from paraffin embedded blocks. After deparaffinization and rehydration, IHC was performed using an UltraSensitiveTM SP IHC Kit (Fuzhou Maixin) and a DAB Detection Kit (Streptavidin-Biotin) (Fuzhou 
Maixin), following the protocol recommended by the manufacturer and described previously[23]. The primary antibodies were anti-HE4 recombinant rabbit monoclonal antibody (1:1000, Abcam, ab109298). The negative control was samples that were incubated without the primary antibody. Slides were assessed by two independent experienced pathologists blinded to the patient's status. In the case of an inconsistent score between them, a third senior pathologist was consulted for the final evaluation. Staining intensity was scored as 0 to 3 [0 (negative), 1 (weak), 2 (moderate) and 3 (strong)]. The heterogeneity of staining was scored as 0 to 3 , depending on the percentage of positively stained tumor cells [0 (0-25\%), $1(25-50 \%), 2$ $(50-75 \%)$ and $3(75-100 \%)]$. The intensity and heterogeneity scores were multiplied to generate the total score (TS). TS $\geq 3$ was considered as high expression of HE4, while TS < 3 was low expression.

\section{Statistical analysis}

The data are presented as mean \pm standard deviation. To determine statistical significance, the ANOVA test, Student's t-test, Mann-Whitney test, chi-squared test, Pearson's correlation test, and Spearman test were performed as appropriate using SPSS 22.0 software. Figures were made with
Graph-Pad Prism 6.0. OS and PFS were evaluated using the Kaplan-Meier method and log-rank test. Cox proportional hazards model was used to evaluate prognostic values of HE4 and eIF3a. All p-values were two-tailed.

\section{Results}

\section{Clinicopathologic variables of patients}

The cohort included 189 women. Specimens included 30 normal ovaries resected during surgery for other gynecologic malignancies, 45 benign ovarian neoplasms, 20 borderline tumors, and 94 malignant ovarian tumors. The histological diagnosis of samples was reconfirmed by a pathologist with expertise in gynecologic cancer. The age of patients at the time of diagnosis was ranged from 25 to 76 years old. The median age was 50 years old, and the mean was 50.69 years old. The mean ages in nonmalignant and malignant groups were $49.32 \pm 10.78$ years and $51.44 \pm$ 10.04 years, respectively $(\mathrm{P}=0.183)$. All EOC patients received platinum/taxane-based postoperative chemotherapy with a mean of 4.94 cycles of chemotherapy. General clinical and pathological information of EOC patients were shown in Table 1. The mean follow-up for the malignant group was $36.19 \pm 14.00$ months.

Table 1. mRNA expressions of HE4 and elF3a and serum CA125 levels in women with primary EOC.

\begin{tabular}{|c|c|c|c|c|c|c|}
\hline & HE4 mRNAa $(n=94)$ & $P$ value & eIF3a mRNA ${ }^{a}(n=94)$ & $P$ value & Serum CA125a $(\mathrm{U} / \mathrm{ml})(\mathrm{n}=90)$ & $P$ value \\
\hline \multicolumn{7}{|l|}{ Age } \\
\hline$<50 y$ & $54.3 \pm 81.4(45)$ & 0.470 & $1.1 \pm 1.5(45)$ & 0.288 & $1811 \pm 2216(43)$ & 0.061 \\
\hline$\geq 50 \mathrm{y}$ & $43.1 \pm 68.1(49)$ & & $0.8 \pm 0.9(49)$ & & $1084 \pm 1223(47)$ & \\
\hline \multicolumn{7}{|c|}{ Histological subtype } \\
\hline Mucinous & $23.0 \pm 27.1(5)$ & 0.206 & $1.5 \pm 1.3(5)$ & 0.266 & $761 \pm 1402(5)$ & 0.514 \\
\hline Serous & $33.4 \pm 33.6(35)$ & & $0.7 \pm 0.9(35)$ & & $1339 \pm 1378(34)$ & \\
\hline Others & $59.2 \pm 91.5(47)$ & & $1.1 \pm 1.4(47)$ & & $1655 \pm 2178(44)$ & \\
\hline \multicolumn{7}{|l|}{ Grade } \\
\hline Grade 1 & $22.1 \pm 27.7(7)$ & 0.363 & $1.1 \pm 1.3(7)$ & 0.582 & $692 \pm 998(7)$ & 0.270 \\
\hline Grade 2 & $57.1 \pm 83.5(54)$ & & $0.8 \pm 1.0(54)$ & & $1321 \pm 1582(53)$ & \\
\hline Grade 3 & $39.8 \pm 64.0(33)$ & & $1.1 \pm 1.5(33)$ & & $1798 \pm 2215(30)$ & \\
\hline \multicolumn{7}{|l|}{ Stage } \\
\hline $\mathrm{I}+\mathrm{II}$ & $32.2 \pm 28.6(13)$ & 0.402 & $1.5 \pm 2.1(13)$ & 0.324 & $277 \pm 494(13)$ & 0.000 \\
\hline $\mathrm{III}+\mathrm{IV}$ & $51.0 \pm 79.3(81)$ & & $0.9 \pm 1.0(81)$ & & $1626 \pm 1863(77)$ & \\
\hline \multicolumn{7}{|c|}{ Residual tumor } \\
\hline$<1 \mathrm{~cm}$ & $46.9 \pm 73.4(78)$ & 0.688 & $0.9 \pm 1.2(78)$ & 0.836 & $1419 \pm 1870(75)$ & 0.591 \\
\hline$>1 \mathrm{~cm}$ & $38.7 \pm 46.2(14)$ & & $0.9 \pm 1.0(14)$ & & $1713 \pm 1392(13)$ & \\
\hline \multicolumn{7}{|c|}{ LN-metastasis } \\
\hline Absent & $65.3 \pm 101.9$ & 0.038 & $1.1 \pm 1.5(34)$ & 0.350 & $926 \pm 1231(34)$ & 0.014 \\
\hline Present & $34.1 \pm 37.4(58)$ & & $0.8 \pm 0.9(58)$ & & $1801 \pm 2024(54)$ & \\
\hline \multicolumn{7}{|l|}{ Ascites } \\
\hline Absent & $48.9 \pm 63.6(30)$ & 0.856 & $1.1 \pm 1.2(30)$ & 0.692 & $798 \pm 1123(29)$ & 0.031 \\
\hline$<500 \mathrm{ml}$ & $47.1 \pm 79.4(17)$ & & $0.8 \pm 0.8(17)$ & & $1569 \pm 1957(15)$ & \\
\hline$>500 \mathrm{ml}$ & $40.4 \pm 62.0(40)$ & & $1.0 \pm 1.4(40)$ & & $1966 \pm 2076(40)$ & \\
\hline \multicolumn{7}{|c|}{ Menopause } \\
\hline Negative & $48.7 \pm 76.8(52)$ & 0.928 & $0.8 \pm 0.9(52)$ & 0.229 & $1169 \pm 1379(51)$ & 0.116 \\
\hline Positive & $50.1 \pm 73.9(40)$ & & $1.2 \pm 1.5(40)$ & & $1819 \pm 2210$ & \\
\hline \multicolumn{7}{|l|}{ NACT } \\
\hline Negative & $47.3 \pm 74.2(78)$ & 0.625 & $0.9 \pm 1.1(78)$ & 0.205 & $1524 \pm 1908$ (77) & 0.030 \\
\hline Positive & $57.7 \pm 79.8(15)$ & & $1.4 \pm 1.5(15)$ & & $879 \pm 688(13)$ & \\
\hline
\end{tabular}

a: The data are shown as Mean \pm SD.

Abbr.: NACT: neoadjuvant chemotherapy; LN: lymph node. 


\section{HE4 mRNA expression in women with primary EOC}

HE4 mRNA expression in 94 women with primary EOC was $48.42 \pm 74.55$ (range: 0.01-343.99), significantly higher than women in the other three groups (Figure 1A, $\mathrm{P}<0.001$ ). HE4 mRNA expression in women with borderline tumors was $12.47 \pm 13.72$, similar to that in the benign tumor group $(4.93 \pm 9.20$, $\mathrm{P}=0.260$ ) but significantly higher than that in the normal ovary group $(1.03 \pm 2.17, \mathrm{P}=0.021)$. The cutoff value of HE4 relative level was 13.99 to discriminate malignant from benign tumors at $68.1 \%$ sensitivity and $93.0 \%$ specificity and was 15.93 to discriminate malignant from borderline tumors at $61.7 \%$ sensitivity and $76.5 \%$ specificity (Figure $1 \mathrm{~B}, \mathrm{P}<0.01$ ).

As shown in Table 1, HE4 mRNA expression significantly correlated with lymph node metastasis in primary EOC. Its relative level in the lymph node metastasis-absent group was much higher than in the lymph node metastasis-present group $(65.31 \pm 101.94$ vs. $34.13 \pm 37.43, \mathrm{P}=0.038$ ). Although it seemed that HE4 expression increased in the sequence of mucinous, serous, and other adenocarcinoma (22.99 \pm 27.08 vs. $33.44 \pm 33.55$ vs. $59.24 \pm 91.48$ ), the difference did not reach significance (Table $1, \mathrm{P}=0.206$ ). Moreover, no correlation was observed between HE4 mRNA expression and other clinicopathologic characteristics which included age, FIGO stage, tumor grade, residual tumor, ascites, neoadjuvant chemotherapy (NACT), and menopause (Table 1).

Serum CA125 levels are listed in Table 1. Its level in the malignant tumor group was highest compared to the other three groups (Figure $1 \mathrm{~A}, \mathrm{P}<0.001$ ), and significantly correlated with FIGO stage, lymph node metastasis, ascites, and NACT (Table 1). Furthermore, Spearman correlation analysis revealed that HE4 mRNA level was positively linear related with serum CA125 (Figure 1C, r=0.530, $\mathrm{P}<0.001$ ).

\section{elF3a mRNA expression in women with primary EOC}

eIF3a mRNA expression in women with primary EOC was $0.95 \pm 1.19$ (range: 0.06-7.46). There was no significant difference among malignant tumor, borderline tumor, benign tumor, and the normal ovary group (Figure $1 \mathrm{~A}, \mathrm{P}=0.668$ ). Furthermore, no significant association was found between eIF3a mRNA expression and clinicopathologic features of primary EOC patients (Table 1). There was also no correlation to be found between eIF3a mRNA level and serum CA125 $(r=-0.116, P=0.158)$.

The mRNA expressions of HE4 and eIF3a were in a positive linear correlation among women with primary EOC (Figure 1C, $\mathrm{r}=0.310, \mathrm{P}=0.002$ ).

\section{Correlations of mRNA expressions of HE4 and eIF3a with primary EOC survival}

To demonstrate a potential difference in survival according to the quantitative levels of HE4 and eIF3a, we performed the Kaplan-Meier method and log-rank test of PFS and OS with the respective levels 1) divided into four quartiles and 2) grouped by greater than one or not $(>1$ or $<1)$.
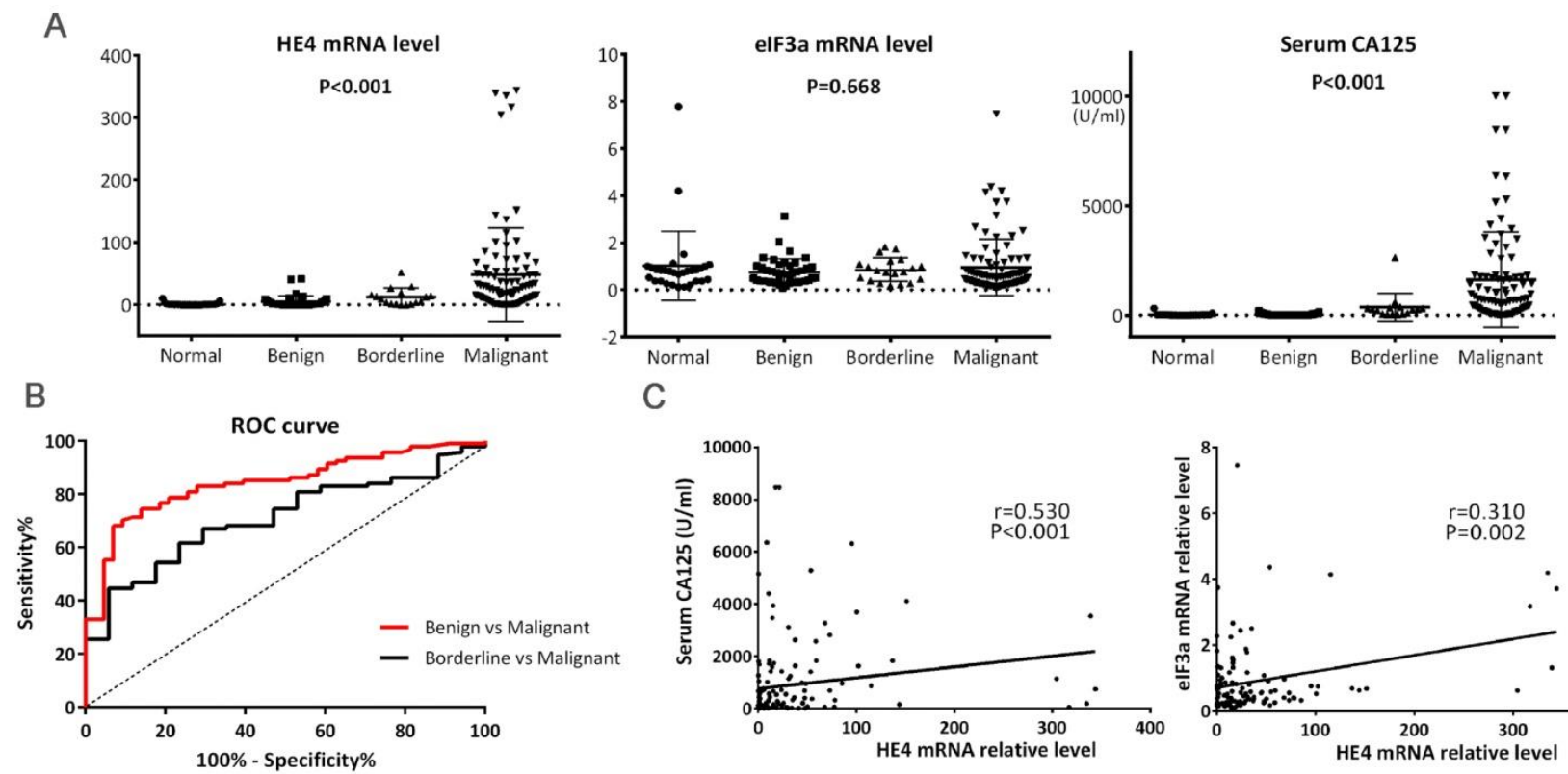

Figure 1. (A) Levels of HE4 mRNA, elF3a mRNA, and serum CA125 among tumors. HE4 mRNA and serum CA125 levels were significantly increased in malignant tumors. (B) ROC curves for discrimination of malignant tumors from benign and borderline tumors using HE4 mRNA levels. The area under curve (AUC) for Benign vs. Malignant and Borderline vs. Malignant were $0.842(95 \% \mathrm{Cl}, 0.775-0.909)$ and $0.710(95 \% \mathrm{Cl}, 0.599-0.821)$, respectively. Both $\mathrm{P}<0.01$. (C) Correlations of $\mathrm{HE} 4$ mRNA with serum CA125 and elF3a mRNA. Spearman's and Pearson's correlation test were used, respectively. 
For HE4, we did not find any statistical correlation with PFS or OS among four quartiles, but the relative level of HE4 greater than one $(>1)$ was significantly associated with increased OS (Figure 2A). Since the median OS was not reached yet, the mean OS increased from 31.36 months $(95 \% \mathrm{CI}$, 16.34-46.39 months) for HE4 less than one $(<1)$ to 48.04 months (95\% CI, 44.04-52.04 months) for HE4 greater than one $(>1)(\mathrm{P}=0.009)$. Furthermore, we even found that OS in patients with HE4 greater than 10, 50, and 100 were also significantly higher than that less than one (47.49, 51.34, 52.70 months, $\mathrm{P}=0.016,0.009,0.049$ respectively). No significant difference existed with PFS for HE4.

For eIF3a, we found the median PFS increased from 22.93 months (95\% CI, 12.63-33.23 months) for patients in the first quartile to 38.54 months $(95 \% \mathrm{CI}$, 14.63-62.45 months) in the upper fourth quartile (Figure 2B, $\mathrm{P}=0.075$ ), but we did not find a similar correlation between PFS and eIF3a level greater than one or not. It was also found that no correlation existed between OS and eIF3a mRNA level among any groups.

Multivariable analysis further confirmed an independent prognostic value of the relative mRNA level of HE4 greater than one for OS (Hazard Ratio, $0.069,95 \% \mathrm{CI}, 0.009-0.530, \mathrm{P}=0.010$ ), but this was not the case for PFS (Table 2, $\mathrm{P}=0.445$ ). Multivariable analysis did not indicate the prognostic significance of eIF3a mRNA level for both PFS and OS. As shown in Table 2, CA125 and optimal cytoreduction (residual tumor $<1 \mathrm{~cm}$ ) were also found to significantly correlate with OS ( $\mathrm{P}=0.018$ and 0.001 , respectively).

\section{HE4 protein level by IHC detection and the correlation with HE4 mRNA level}

We further compared the mRNA and protein levels of HE4 in this study. IHC detection was performed using paraffin samples from the same participants to validate HE4 protein levels (Figure 3). Primary EOC group had the highest expression of HE4 compared to the other three groups (malignant vs. normal, benign, and borderline group, $67.2 \%$ vs. 7.7, 35.7, and 46.7\%, P<0.001). Among the clinicopathologic characteristics in the primary EOC group, only residual tumor correlated with the IHC result of HE4. HE4 protein level was significantly higher in residual tumor $>1 \mathrm{~cm}$ group than $<1 \mathrm{~cm}$ group (high expression ratio, $100 \%$ vs. $61.4 \%$; TS, 6.00 \pm 2.00 vs. $3.61 \pm 2.74, \mathrm{P}<0.05)$. By analyzing PFS, we found that high HE4 expression decreased the mean PFS from 38.65 months (95\% CI, 29.58-47.73 months) to 28.18 months (95\% CI, 22.91-33.44 months) compared to low HE4 expression (Figure 2C, $\mathrm{P}=0.093)$. Furthermore, the mean OS of EOC patients with high HE4 expression was significantly worse than those with low HE4 expression (Figure 2D, 37.59 vs. 53.47 months; $95 \%$ CI, 32.57-42.61 vs. $48.88-58.06$ months, $\mathrm{P}=0.022$ ).

In the present study, the relative level of HE4 mRNA did not correlate with TS of HE4 in malignant patients $(\mathrm{r}=0.066, \mathrm{P}=0.596)$. HE4 mRNA levels also did not show a significant difference between high and low IHC expressions of HE4 (44.11 \pm 59.26 vs. $55.71 \pm$ 95.98, $\mathrm{P}=0.544)$.

Table 2. Univariable and multivariable Cox regression analysis of HE4 mRNA expression with PFS and OS in EOC.

\begin{tabular}{|c|c|c|c|c|c|c|c|c|}
\hline \multirow[b]{2}{*}{ Variables } & \multicolumn{4}{|l|}{ PFS } & \multicolumn{4}{|l|}{ OS } \\
\hline & $\begin{array}{l}\text { Univariable } \\
\text { HR }(95 \% \text { CI) }\end{array}$ & $P$ value & $\begin{array}{l}\text { Multivariablea } \\
\text { HR }(95 \% \text { CI) }\end{array}$ & $P$ value & $\begin{array}{l}\text { Univariable } \\
\text { HR }(95 \% \text { CI) }\end{array}$ & $P$ value & $\begin{array}{l}\text { Multivariablea } \\
\text { HR }(95 \% \text { CI) }\end{array}$ & $P$ value \\
\hline $\begin{array}{l}\text { FIGO Stage } \\
(\mathrm{I}+\mathrm{II} \text { vs. III+IV) }\end{array}$ & $\begin{array}{l}2.297 \\
(0.904-9.478)\end{array}$ & 0.073 & -- & 0.171 & $\begin{array}{l}3.595 \\
(0.485-26.639)\end{array}$ & 0.211 & -- & 0.425 \\
\hline $\begin{array}{l}\text { Tumor grade } \\
\text { (G1 vs. G2 vs. G3) }\end{array}$ & $\begin{array}{l}1.210 \\
(0.710-2.062)\end{array}$ & 0.484 & -- & 0.678 & $\begin{array}{l}1.008 \\
(0.499-2.036)\end{array}$ & 0.982 & -- & 0.550 \\
\hline $\begin{array}{l}\text { Histological subtype } \\
\text { (mucinous vs. serous vs. others) }\end{array}$ & $\begin{array}{l}0.710 \\
(0.430-1.173)\end{array}$ & 0.181 & -- & 0.395 & $\begin{array}{l}0.485 \\
(0.276-0.855)\end{array}$ & 0.012 & -- & 0.078 \\
\hline $\begin{array}{l}\text { HE4 relative level } \\
(>1 \text { vs. }<1)\end{array}$ & $\begin{array}{l}1.141 \\
(0.353-3.693)\end{array}$ & 0.826 & -- & 0.445 & $\begin{array}{l}0.288 \\
(0.106-0.779)\end{array}$ & 0.014 & $\begin{array}{l}0.069 \\
(0.009-0.530)\end{array}$ & 0.010 \\
\hline $\begin{array}{l}\text { eIF3a relative level } \\
(<25 \% \text { vs. }>75 \%)\end{array}$ & $\begin{array}{l}0.523 \\
(0.232-1.179)\end{array}$ & 0.118 & -- & 0.461 & $\begin{array}{l}0.416 \\
(0.129-1.346)\end{array}$ & 0.143 & -- & 0.841 \\
\hline CA125 & $\begin{array}{l}1.000 \\
(1.000-1.001)\end{array}$ & 0.000 & $\begin{array}{l}1.000 \\
(1.000-1.001)\end{array}$ & 0.001 & $\begin{array}{l}1.000 \\
(1.000-1.000)\end{array}$ & 0.002 & $\begin{array}{l}1.000 \\
(1.000-1.001)\end{array}$ & 0.018 \\
\hline $\begin{array}{l}\text { Residual tumor } \\
(>1 \text { vs. }<1)\end{array}$ & $\begin{array}{l}1.220 \\
(0.515-2.890)\end{array}$ & 0.652 & -- & 0.573 & $\begin{array}{l}3.041 \\
(1.259-7.349)\end{array}$ & 0.013 & $\begin{array}{l}11.029 \\
(2.774-43.842)\end{array}$ & 0.001 \\
\hline $\begin{array}{l}\text { Lymph node metastasis } \\
\text { (present } v \text { s. absent) }\end{array}$ & $\begin{array}{l}2.268 \\
(1.118-4.602)\end{array}$ & 0.023 & -- & 0.057 & $\begin{array}{l}1.595 \\
(0.631-4.029)\end{array}$ & 0.324 & -- & 0.522 \\
\hline $\begin{array}{l}\text { Neoadjuvant chemotherapy } \\
\text { (present } v s . \text { absent) }\end{array}$ & $\begin{array}{l}1.286 \\
(0.572-2.890)\end{array}$ & 0.542 & -- & 0.160 & $\begin{array}{l}0.562 \\
(0.132-2.393)\end{array}$ & 0.436 & -- & 0.490 \\
\hline $\begin{array}{l}\text { Menopause } \\
\text { (present } v s . \text { absent) }\end{array}$ & $\begin{array}{l}1.062 \\
(0.587-1.921)\end{array}$ & 0.843 & -- & 0.708 & $\begin{array}{l}0.483 \\
(0.200-1.166)\end{array}$ & 0.106 & -- & 0.649 \\
\hline $\begin{array}{l}\text { Ascites } \\
\text { (present vs. absent) }\end{array}$ & $\begin{array}{l}1.710 \\
(0.901-3.247)\end{array}$ & 0.101 & -- & 0.980 & $\begin{array}{l}4.213 \\
(1.250-14.199)\end{array}$ & 0.020 & -- & 0.627 \\
\hline
\end{tabular}


A

HE4 mRNA level

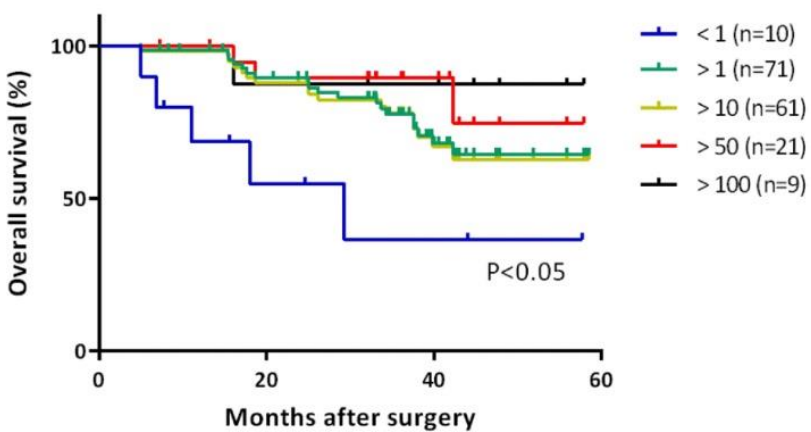

C

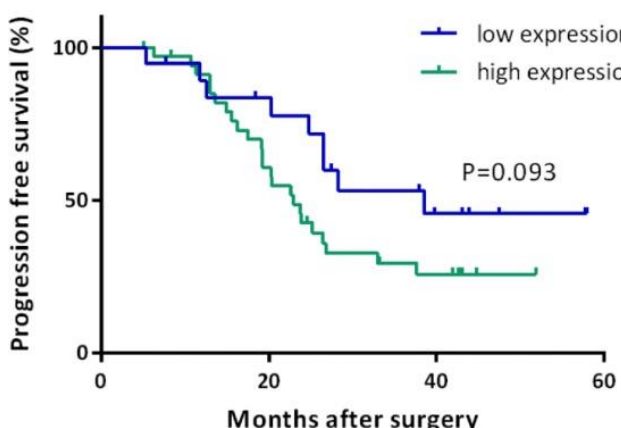

B

elF3a mRNA level

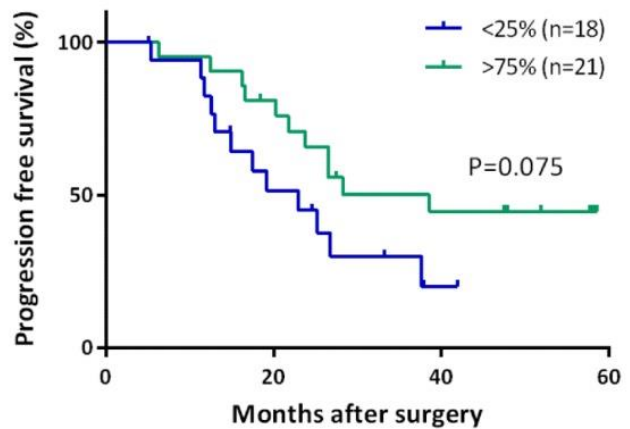

D

HE4 protein level

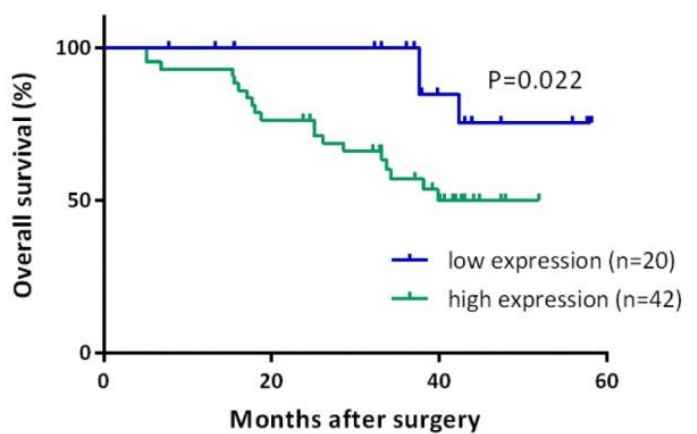

Figure 2. Kaplan-Meier curves for progression-free survival (PFS) and overall survival (OS) of women with EOC. (A) OS curves indicated the prolonged OS of patients with HE4 mRNA level greater than 1, 10, 50, and 100 compared to less than 1. All P<0.05. (B) PFS curve indicated patients with elF3a mRNA level in the first quartile $(<25 \%)$ recurred earlier than those in the upper fourth quartile $(>75 \%)$. $P=0.075$. PFS curve $(C)$ and OS curve $(D)$ for HE4 protein levels detected by IHC indicated worse survival of patients with high expression of HE4 protein than those with low expression of HE4 protein. $P=0.093$ and 0.022 , respectively.
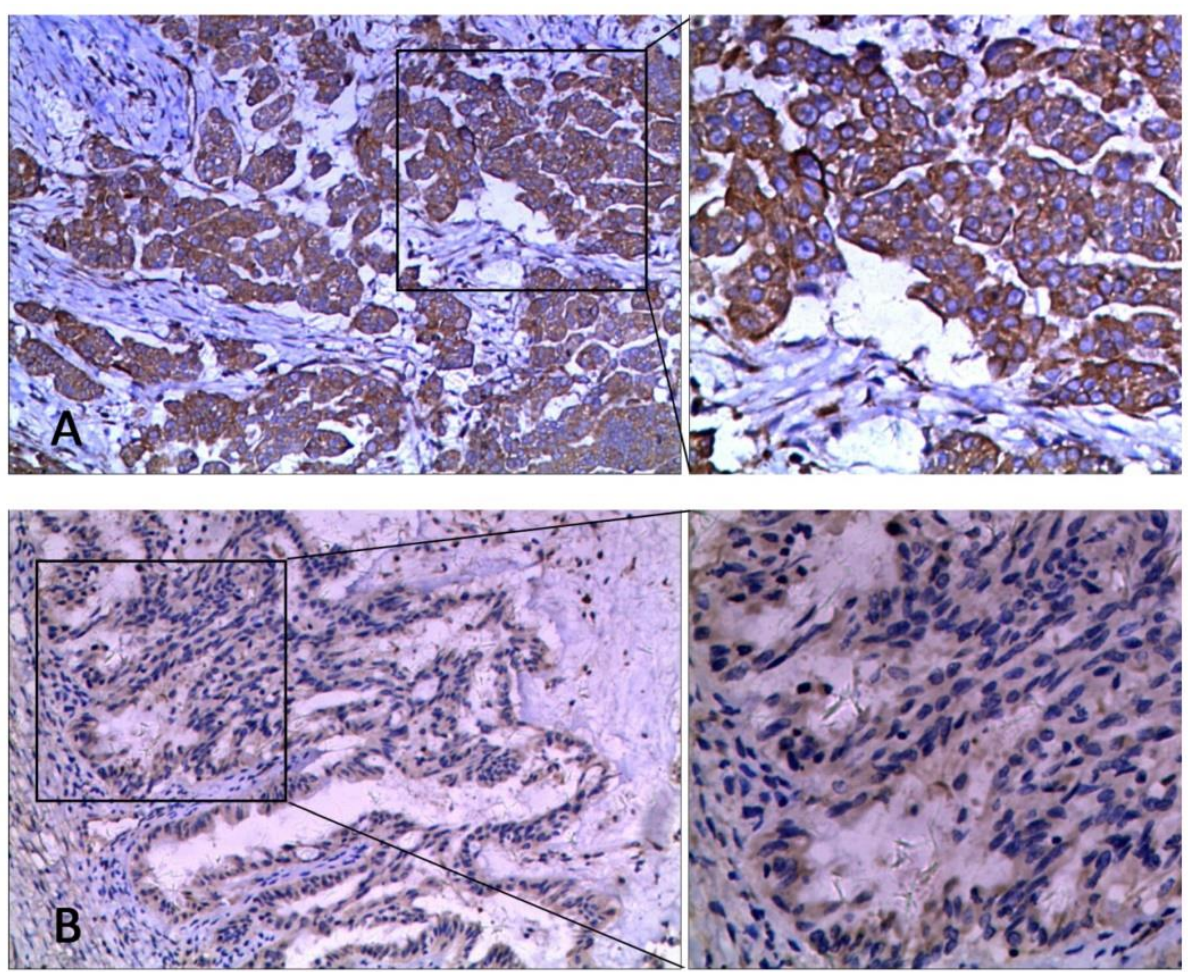

Figure 3. The representative images of HE4 staining by IHC in ovarian tissues at 100x and 200x magnification. (A) High expression, (B) Low expression. 


\section{Discussion}

Numerous studies have reported expressions of HE4 protein in serum and in tumor specimens of women with EOC[3-12], but little was reported about the expression of HE4 mRNA[24, 25]. Prior studies only reported a significantly increased mRNA level of HE4 in EOC[24, 25]. In the present study, we not only reported the increased mRNA expression of HE4, but also indicated cutoff values for the relative level of HE4 mRNA to discriminate EOC from benign and borderline tumors at comparatively high sensitivity and specificity. Furthermore, we also found that high levels of HE4 mRNA predict a better overall survival in primary EOC. To our knowledge, this is the first study to report the prognostic value of HE4 mRNA levels in malignancy. Similarly, no previous report was about eIF3a mRNA in malignancy, although a number of studies revealed the role of eIF3a protein in many types of cancer[20-23]. The first report about eIF3a protein levels in women with EOC and the correlation between eIF3a protein and HE4 protein was published by our group[23]. To our knowledge, the present study is also the first investigation about the expression and clinical importance of eIF3a mRNA in EOC, as well as the association of HE4 mRNA with eIF3a mRNA.

A negative correlation of HE4 with lymph node metastasis is reported by this study. We have not found any association between the HE4 mRNA level and age, FIGO stage, tumor grade, residual tumor, ascites, NACT, and menopause which were previously shown to correlate with the serum level or IHC expression of HE4[3, 6]. Our data indicated that HE4 mRNA levels have a significant prognostic value in primary EOC, but interestingly, its negative correlation with the survival of patients is contrary to those results on protein level in previous reports [4, 5, 7-10] as well as in our own study. Consequently, to investigate the relationship between mRNA and protein levels of HE4 in this study, we performed IHC and demonstrated that HE4 mRNA level is not associated with its protein level. Our results arouse the curiosity regarding the mechanism of HE4's function, especially the role of HE4 in the malignant biological behaviors of ovarian cancer.

Although a number of reports have shown that increased HE4 protein level correlates with poor survival in EOC $[3,6]$, the underlying mechanism is unclear and the effect of HE4 protein in the tumorigenesis of EOC remains controversial[9, 26-28]. Several recent studies confirmed that HE4 overexpression promotes proliferation, invasion and metastasis of ovarian cancer cells $[9,26]$, yet some earlier work showed decreased growth and invasiveness of ovarian cancer cells induced by HE4 overexpression[27, 28]. Interestingly, Huan Wang et al. found that at low concentrations $(0.083-0.2 \mu \mathrm{g} / \mathrm{ml})$, exogenous HE4 protein was able to significantly increase viability, proliferation, and colony formation of SKOV-3 cells, but higher concentration $(1 \mu \mathrm{g} / \mathrm{ml})$ of exogenous HE4 protein did not further enhance the above effects[29]. It seemed that the effect of HE4 protein on malignant cells varied depending on its levels. It was previously reported that some proteins, such as Nox4[30] and histone H3[31], could cause feedback inhibition on their own mRNA expressions. Here, we speculate that HE4 may have a similar effect. HE4 mRNA and protein expressions initially increase with the malignant transformation of ovarian cells. As HE4 protein reaches a higher level and accumulates constantly, it causes feedback inhibition on its own mRNA, leading to an unparalleled expression profile of HE4 mRNA and protein. This could explain our observations that poor survival was associated with high levels of HE4 protein and low levels of HE4 mRNA, and that HE4 mRNA negatively correlated with lymph node metastasis in the present study. The speculation calls for further investigations.

Our study indicated that HE4 mRNA played a unique role in predicting the prognosis of EOC, which was different from that of its protein. Furthermore, the high correlation between HE4 mRNA level and serum CA125 level increases the prognostic significance of HE4 mRNA in EOC.

Unfortunately, we do not find any significance about eIF3a mRNA distribution among ovarian tumors and its correlation with clinicopathologic features of primary EOC. The varying range of eIF3a mRNA level is much smaller than that of HE4 mRNA level in this study, which implies a stable role of eIF3a in EOC. However, there is still a positive linear correlation between mRNA expressions of HE4 and eIF3a, similar to their protein levels[23], suggesting some connections between them in their molecular mechanism.

As retrospective research, there are regretting limitations. One is that there is no data on HE4 serum levels available to investigate its correlation with the HE4 mRNA level. Another is that the period of follow-up was relatively short to observe the differences in survival of EOC. Longer follow-up and an increased number of patients may lead to further confirmation of our study.

In summary, our study demonstrated that high levels of HE4 mRNA could discriminate malignant from benign tumors in primary EOC and show a better prognosis than low levels of HE4 mRNA. Unlike HE4, eIF3a was not found to have a similar role in EOC. Further investigations are required to confirm the unique independent role of HE4 mRNA 
and offer new insight into the molecular mechanism between HE4 and eIF3a.

\section{Abbreviations}

HE4: human epididymis protein 4; EOC: epithelial ovarian cancer; eIF3a: eukaryotic translation initiation factor 3a; IHC: immunohistochemistry; KPS: Karnofsky Performance Status; FIGO: Federation of Gynecology and Obstetrics; OS: overall survival; PFS: progression free survival; NACT: neoadjuvant chemotherapy.

\section{Acknowledgements}

We thank Wei Mo, Ji-ye Yin (Institute of Clinical Pharmacology, Xiangya Hospital, Central South University, Changsha, Hunan, China) and BrandonLuke L. Seagle (Department of Obstetrics and Gynecology, Division of Gynecologic Oncology, Prentice Women's Hospital, Northwestern University Feinberg School of Medicine, Chicago, IL, USA) for revising this manuscript. This work was supported by the Key program of Hunan Provincial Science \& Technology Department (2013FJ2009 to C-H Luo); the Hunan Provincial Natural Science Foundation of China (2015JJ2093 to J Wang); and the National Natural Science Foundation of China (81522048).

\section{Competing Interests}

The authors have declared that no competing interest exists.

\section{References}

1. Morgan RJ, Jr., Armstrong DK, Alvarez RD, Bakkum-Gamez JN, Behbakht K, Chen LM, et al. Ovarian Cancer, Version 1.2016, NCCN Clinical Practice Guidelines in Oncology. J Natl Compr Canc Netw. 2016; 14: 1134-63.

2. Hellstrom I, Raycraft J, Hayden-Ledbetter M, Ledbetter JA, Schummer M, McIntosh M, et al. The HE4 (WFDC2) protein is a biomarker for ovarian carcinoma. Cancer Res. 2003; 63: 3695-700.

3. Li J, Dowdy S, Tipton T, Podratz K, Lu WG, Xie X, et al. HE4 as a biomarker for ovarian and endometrial cancer management. Expert Rev Mol Diagn. 2009; 9: $555-66$.

4. Karlsen MA, Hogdall EV, Christensen IJ, Borgfeldt C, Kalapotharakos G, Zdrazilova-Dubska L, et al. A novel diagnostic index combining HE4, CA125 and age may improve triage of women with suspected ovarian cancer - An international multicenter study in women with an ovarian mass. Gynecol Oncol. 2015; 138: 640-6.

5. Romagnolo C, Leon AE, Fabricio ASC, Taborelli M, Polesel J, Del Pup L, et al. HE4, CA125 and risk of ovarian malignancy algorithm (ROMA) as diagnostic tools for ovarian cancer in patients with a pelvic mass: An Italian multicenter study. Gynecol Oncol. 2016; 141: 303-11.

6. Scaletta G, Plotti F, Luvero D, Capriglione S, Montera R, Miranda A, et al. The role of novel biomarker HE4 in the diagnosis, prognosis and follow-up of ovarian cancer: a systematic review. Expert Rev Anticancer Ther. 2017; 17: 827-39.

7. Zhu LC, Gao J, Hu ZH, Schwab CL, Zhuang HY, Tan MZ, et al. Membranous expressions of Lewis y and CAM-DR-related markers are independent factors of chemotherapy resistance and poor prognosis in epithelial ovarian cancer. Am J Cancer Res. 2015; 5: 830-43.

8. Vallius T, Hynninen J, Auranen A, Carpen O, Matomaki J, Oksa S, et al. Serum HE4 and CA125 as predictors of response and outcome during neoadjuvant chemotherapy of advanced high-grade serous ovarian cancer. Tumour Biol. 2014; 35: 12389-95

9. Moore RG, Hill EK, Horan T, Yano N, Kim K, MacLaughlan S, et al. HE4 (WFDC2) gene overexpression promotes ovarian tumor growth. Sci Rep. 2014; 4: 3574
10. Angioli R, Capriglione S, Aloisi A, Guzzo F, Luvero D, Miranda A, et al. Can HE4 predict platinum response during first-line chemotherapy in ovarian cancer? Tumour Biol. 2014; 35: 7009-15.

11. Steffensen KD, Waldstrom M, Brandslund I, Jakobsen A. Prognostic impact of prechemotherapy serum levels of HER2, CA125, and HE4 in ovarian cancer patients. Int J Gynecol Cancer. 2011; 21: 1040-7.

12. Rosen DG, Wang L, Atkinson JN, Yu Y, Lu KH, Diamandis EP, et al. Potential markers that complement expression of CA125 in epithelial ovarian cancer. Gynecol Oncol. 2005; 99: 267-77.

13. Bignotti E, Ragnoli M, Zanotti L, Calza S, Falchetti M, Lonardi S, et al. Diagnostic and prognostic impact of serum HE4 detection in endometrial carcinoma patients. Br J Cancer. 2011; 104: 1418-25.

14. Jiang Y, Wang C, Lv B, Ma G, Wang L. Expression level of serum human epididymis 4 and its prognostic significance in human non-small cell lung cancer. Int J Clin Exp Med. 2014; 7: 5568-72.

15. Huang T, Jiang SW, Qin L, Senkowski C, Lyle C, Terry K, et al. Expression and diagnostic value of HE4 in pancreatic adenocarcinoma. Int J Mol Sci. 2015; 16: 2956-70.

16. Lee AS, Kranzusch PJ, Cate JH. eIF3 targets cell-proliferation messenger RNAs for translational activation or repression. Nature. 2015; 522: 111-4.

17. Harel-Sharvit L, Eldad N, Haimovich G, Barkai O, Duek L, Choder M. RNA polymerase II subunits link transcription and mRNA decay to translation. Cell. 2010; 143: 552-63.

18. Bolger TA, Folkmann AW, Tran EJ, Wente SR. The mRNA export factor Gle1 and inositol hexakisphosphate regulate distinct stages of translation. Cell. 2008; 134: 624-33.

19. Isken O, Kim YK, Hosoda N, Mayeur GL, Hershey JW, Maquat LE. Upf1 phosphorylation triggers translational repression during nonsense-mediated mRNA decay. Cell. 2008; 133: 314-27.

20. Spilka R, Ernst C, Mehta AK, Haybaeck J. Eukaryotic translation initiation factors in cancer development and progression. Cancer Lett. 2013; 340: 9-21.

21. Hershey JW. The role of eIF3 and its individual subunits in cancer. Biochim Biophys Acta. 2015; 1849: 792-800.

22. Zhang Y, Yu JJ, Tian Y, Li ZZ, Zhang CY, Zhang SF, et al. eIF3a improve cisplatin sensitivity in ovarian cancer by regulating XPC and p27Kip1 translation. Oncotarget. 2015; 6: 25441-51.

23. Wang J, Luo C, Wang Y, Tang Y, Fang K, Zeng L, et al. [Correlation between eIF3a and HE4 expression and ovarian cancer]. Zhong Nan Da Xue Xue Bao Yi Xue Ban. 2014; 39: 1240-5.

24. Fawzy A, Mohamed MR, Ali MA, Abd El-Magied MH, Helal AM. Tissue CA125 and HE4 Gene Expression Levels Offer Superior Accuracy in Discriminating Benign from Malignant Pelvic Masses. Asian Pac J Cancer Prev. 2016; 17: 323-33.

25. Huhtinen K, Suvitie P, Hiissa J, Junnila J, Huvila J, Kujari H, et al. Serum HE4 concentration differentiates malignant ovarian tumours from ovarian endometriotic cysts. Br J Cancer. 2009; 100: 1315-9.

26. Zhu L, Zhuang H, Wang H, Tan M, Schwab CL, Deng L, et al. Overexpression of HE4 (human epididymis protein 4) enhances proliferation, invasion and metastasis of ovarian cancer. Oncotarget. 2016; 7: 729-44.

27. Kong X, Chang X, Cheng H, Ma R, Ye X, Cui H. Human epididymis protein 4 inhibits proliferation of human ovarian cancer cells via the mitogen-activated protein kinase and phosphoinositide 3-kinase/AKT pathways. Int J Gynecol Cancer. 2014; 24: 427-36.

28. Gao L, Cheng HY, Dong L, Ye X, Liu YN, Chang XH, et al. The role of HE4 in ovarian cancer: inhibiting tumour cell proliferation and metastasis. J Int Med Res. 2011; 39: 1645-60.

29. Wang H, Zhu L, Gao J, Hu Z, Lin B. Promotive role of recombinant HE4 protein in proliferation and carboplatin resistance in ovarian cancer cells. Oncol Rep. 2015; 33: 403-12.

30. Haurani MJ, Cifuentes ME, Shepard AD, Pagano PJ. Nox4 oxidase overexpression specifically decreases endogenous Nox4 mRNA and inhibits angiotensin II-induced adventitial myofibroblast migration. Hypertension. 2008; 52: 143-9.

31. Lee KH, Lee NJ, Hyun S, Park YK, Yang EG, Lee JK, et al. Histone H3 $\mathrm{N}$-terminal peptide binds directly to its own mRNA: a possible mode of feedback inhibition to control translation. ChemBioChem. 2009; 10: 1313-6. 